\title{
Criança no tratamento final contra o câncer e seu olhar para o futuro
}

\author{
Child finishing cancer treatment: \\ Looking at the future
}

\author{
Lara de Faria LANZA \\ Elizabeth Ranier Martins do VALLE ${ }^{2}$
}

\begin{abstract}
Resumo
Há algumas décadas, o câncer infantil era considerado uma doença fatal. Com a melhora nos procedimentos terapêuticos e nos métodos de detecção precoce, o número de crianças que sobrevivem vem aumentando, ocorrendo um direcionamento da atenção para o viver com câncer assim como para as necessidades desses sobreviventes. O presente estudo teve por objetivo compreender, por meio de uma análise fenomenológica, o sentido que a criança que está finalizando seu tratamento contra o câncer atribui ao próprio futuro. Foram realizadas seis entrevistas com crianças entre oito e treze anos e, a partir das convergências e divergências encontradas em seus relatos, emergiram as categorias de análise. A análise de conteúdo dos relatos revelou que, quando o tratamento está terminando e a criança já se encontra sem os sintomas da doença, permanecem ainda por algum período as antigas referências utilizadas na época do tratamento. As crianças falam de seu passado e fazem suposições do que poderá acontecer. Expressam o desejo de retomar sua aparência física anterior e as atividades interrompidas ou dificultadas pela doença. Ao longo de todo esse processo, elas se defrontam com o paradoxo vida e morte e conseguem manter uma visão positiva de futuro, almejando a retomada do projeto de vida e amplitude de possibilidades com a retomada da saúde.
\end{abstract}

Palavras-chave: Criança; Neoplasia; Taxa de sobrevida.

\begin{abstract}
For some decades childhood cancer has been considered a fatal disease. However, with improvements in therapeutic procedures and early detection methods, the number of children who survive is increasing, with the care becoming directed toward living with cancer as well as toward the needs of these survivors. This study aimed to comprehend, through phenomenological analysis, the feelings that children, who are finishing their cancer treatment, attributed to their future. Six interviews were conducted with children aged eight to thirteen years and from the convergences and

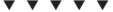

1 Universidade de São Paulo, Escola de Enfermagem de Ribeirão Preto, Programa de Pós-Graduação em Enfermagem Psiquiátrica. Av. dos Bandeirantes, 3900, Ribeirão Preto, SP, Brasil. Correspondência para/Correspondence to: L. F. LANZA. E-mail:<laralanza@gmail.com>.

2 Universidade de São Paulo, Escola de Enfermagem de Ribeirão Preto, Departamento de Enfermagem Psiquiátrica e Ciências Humanas. Ribeirão Preto, SP, Brasil.

Artigo elaborado a partir da dissertação de L.F. LANZA, intitulada "Ser-criança-com-câncer em etapa final de tratamento: sua visão de futuro". Universidade de São Paulo, 2009.

Apoio: Coordenação de Aperfeiçoamento de Pessoal de Nível Superior.
\end{abstract}


divergences in their reports the categories of analysis emerged. The content analysis of the reports revealed that when the treatment is finished and the child has no disease symptoms the old references used at the time of treatment still remain for some time. The children spoke about their past and made assumptions regarding what might happen. They expressed the desire to regain their prior physical appearance, and resume the activities that were interrupted or impeded by the disease. Throughout this process they were faced with the life and death paradox, yet managed to maintain a positive outlook for the future, aiming to resume the life project and enjoy a range of possibilities with the return to health.

Keywords: Child; Neoplasms; Survival rate.

O câncer, embora esteja em nosso meio há muitos séculos, somente nas últimas décadas vem ganhando uma dimensão mais ampla, uma vez que é um problema de saúde pública mundial. Ele tem-se destacado nas causas de mortalidade no Brasil, o que evidencia a importância dos aspectos preventivos e do tratamento precoce contra essa doença (Nascimento, 2003). Historicamente, entre 1950 e 1960, o câncer infantil era considerado uma doença fatal, e as informações sobre a doença não eram compartilhadas com a criança. Nessa época, o tratamento tinha como objetivo amenizar o sofrimento da criança, enquanto as famílias eram preparadas para a inevitabilidade da morte. Já na década de 1970, o foco foi então substituído, deixando de ser o de "morrer" para "viver com uma condição de vida ameaçadora"; a partir do início da década de 1980, vem ocorrendo um direcionamento da atenção para o viver com câncer, assim como para as necessidades psicossociais da criança curada (Eiser, 1994).

O câncer infantil corresponde a um grupo de várias doenças que têm, em comum, a proliferação descontrolada de células anormais e que pode ocorrer em qualquer local do organismo. Considera-se câncer na infância toda neoplasia maligna que acomete indivíduos menores de 15 anos (Teixeira, Bruniera, Cusato, \& Borsato, 2000). A progressão do câncer infantil desde o início é insidiosa, e os sintomas, na maioria das vezes, são inespecíficos e só aparecem quando a doença já atingiu estágios mais avançados, o que pode dificultar o diagnóstico (Ayoub, Fontes, Santos, \& Moreira, 2000; Camargo $\&$ Lopes, 2000). Sua detecção precoce é o fator mais importante para o sucesso terapêutico, com possibilidade de cura total, e pode ajudar a determinar o prognóstico e o esquema terapêutico, doença - o que se denomina estadiamento (Ayoub et al., 2000; Camargo \& Lopes, 2000).

\section{A criança com câncer e a relação com os familiares e a equipe de saúde}

O câncer não afeta apenas a criança enferma, mas estende-se a todo o universo familiar, impondo mudanças, exigindo reorganização na dinâmica familiar para incorporar, às atividades cotidianas, os cuidados que a doença e o tratamento exigem, podendo também afetar os relacionamentos interpessoais. O diagnóstico vem carregado de temores e preocupações, e o modo de enfrentamento da doença/tratamento dependerá do suporte e da estrutura familiares. A doença implica uma série de complicações físicas, emocionais, sociais e econômicas para a vida dos sujeitos enfermos, assim como sérios comprometimentos para suas famílias. Essas mudanças, muitas vezes radicais, alteram, em algum nível, os papéis familiares e sociais (Carvalho, 2008).

O tratamento contra o câncer infantil, na maioria das vezes, é bastante demorado, expondo a criança a um período considerável de hospitalização e a procedimentos invasivos e desagradáveis, tanto física quanto emocionalmente. Para adaptar-se a essa nova situação, a criança utiliza-se de estratégias de enfrentamento, as quais serão articuladas de acordo com as características pessoais da criança, suas crenças e valores em decorrência dos fatores a que estão expostas (Motta \& Enumo, 2004).

É muito importante a comunicação entre a equipe de saúde, a criança e a família, sendo que a criança precisa estar informada sobre seu próprio tratamento, após confirmado seu diagnóstico, de 
maneira adequada ao seu nível de compreensão, e a equipe e a família precisam estar atentas às significações atribuídas pela criança aos diversos aspectos que envolvem esse tratamento, tais como hospitalização, quimioterapia, cirurgia, possibilidade de cura, dentre outros (Valle, 1997). Alguns motivos apresentados na literatura pela recusa, não cooperação e abandono do tratamento incluem desconforto físico do paciente, o medo dos pais de perderem seu papel como pais, não entendimento e incerteza sobre os méritos da medicação, falha ou inadequação na comunicação sobre o diagnóstico e o tratamento e seus efeitos secundários. A insuficiência e a impropriedade da comunicação entre o médico, o paciente e a família correspondem a uma das causas mais importantes da não cooperação (Spinetta et al., 2004).

Como toda doença grave, o câncer confronta a criança doente e sua família com a possibilidade de morte iminente, desencadeando profundas transformações em suas vidas. Desde o momento em que o diagnóstico é comunicado à família, profundas modificações podem ocorrer, afetando não só a unidade familiar, mas também o relacionamento entre seus membros e entre outras pessoas. São comuns, nessa fase, reações de incredibilidade, de questionamentos sobre a validade do diagnóstico, a busca de explicações para essa realidade, tentando atribuir uma causa à doença (Valle, 2003). Carvalho (2008) refere a importância de os profissionais da equipe de saúde estarem atentos às condições emocionais, socioeconômicas e culturais dos pacientes e de seus familiares, visto ser de acordo com esse contexto sociofamiliar que se vai responder à situação de doença em toda sua complexidade e singularidade.

\section{Aspectos da sobrevida da criança com câncer}

A melhoria na precisão dos métodos de diagnóstico precoce, o desenvolvimento de tratamentos mais efetivos no controle dos sintomas clínicos e o avanço nos cuidados de suporte têm substancialmente melhorado as perspectivas de vida de crianças com o diagnóstico de câncer. O prognós- tico do câncer na infância melhorou muito, podendo-se alcançar taxas de sobrevida gerais superiores a 50\% (Kennedy, 2003). Dados encontrados na literatura da área mostram que, a partir de 1997, $78 \%$ dos casos diagnosticados como câncer infantil têm alcançado a cura, devido ao desenvolvimento de avançadas técnicas e tratamentos (National Cancer Policy Board, 2003).

Sobreviver ao tratamento é um processo complexo e depende, em grande parte, dos aspectos objetivos e subjetivos das famílias. A experiência do término da terapêutica está relacionada com o modo como os familiares enfrentaram e se adaptaram à situação da doença e com a maneira pela qual procuraram resgatar sua rotina e planejaram o futuro. Paralelamente à cura, há a constante ameaça de recaída e a possibilidade de recomeçar um novo tratamento, revelando um sentimento de insegurança naqueles que sobreviveram ao câncer. A sobrevivência ao câncer representa o caminho percorrido pelas famílias com suas crianças e adolescentes que terminaram o tratamento, o que remete ainda a um estado de saúde que pode estar acompanhado de sequelas da terapêutica que podem surgir precocemente ou a longo prazo e que têm um significado marcante para os familiares e seus filhos (Ortiz \& Lima, 2007).

Pesquisas e estudos realizados com crianças em etapa final de tratamento contra o câncer não se mostraram suficientes para uma compreensão da sua visão sobre o futuro. Justifica-se, portanto, a importância deste estudo, que teve por objetivo, ao ouvir crianças no término do tratamento contra o câncer, encontrar significados e compreender o sentido que elas atribuem ao próprio futuro.

\section{Método}

Primeiramente, o projeto de pesquisa foi submetido à apreciação do Comitê de Ética em Pesquisa do Hospital das Clínicas da Faculdade de Medicina de Ribeirão Preto da Universidade de São Paulo, o qual foi aprovado com o Processo $n^{\circ} \mathrm{HCRP}$ n12150/2007 em 24/3/2008. Todos os participantes assinaram um Termo de Consentimento Livre e Esclarecido antes de sua participação, que contém 
de maneira clara o objetivo da pesquisa, procedimentos, riscos, desconfortos e benefícios.

A inserção no campo empírico ocorreu um mês antes de iniciar a coleta de dados, por meio de participação em reuniões semanais com a equipe de saúde, quando eram discutidos os casos a serem atendidos durante a semana. Por meio da participação nessas reuniões e contato com a equipe médica, foi possível identificar as crianças a serem convidadas para participação na pesquisa e também a data prevista do retorno ambulatorial. O objetivo do estudo era exposto à criança, estando esta geralmente acompanhada pelo pai e/ou mãe, e o termo de consentimento para a participação na pesquisa era lido para eles. Mediante a assinatura do termo de consentimento pelo responsável e concordância de participação pela criança, ela era convidada para uma "conversa" (a entrevista fenomenológica), iniciada com uma questão norteadora: "Agora que você está finalizando seu tratamento, eu gostaria que você me contasse o que pensa em relação ao seu futuro".

Foi garantido o sigilo em relação aos conteúdos que emergissem durante a entrevista assim como o anonimato. As entrevistas foram realizadas em local reservado, na própria sala de espera, onde as crianças falaram livremente; quando necessário, diante de alguma dificuldade de expressão, foi possível intervir para pedir alguns esclarecimentos. As entrevistas foram gravadas com a autorização dos participantes e, posteriormente, transcritas. Imediatamente após as entrevistas, foram registradas observações da pesquisadora que se mostraram importantes, tais como expressões da criança, intervenções externas, conforme metodologia de pesquisa qualitativa de abordagem fenomenológica (Martins \& Bicudo, 1989).

O número de participantes foi definido no decorrer do processo, após uma reflexão dos pesquisadores sobre os discursos obtidos. As crianças descreveram de forma espontânea as situações que acreditavam ser relativas ao fenômeno que estava sendo investigado, e o pesquisador, orientando-se por um sentido, ou seja, pelo conhecimento imediato, intuitivo, que tem desse fenômeno, foi capaz 292 de identificar o momento em que as falas se mostra- vam convergentes, indicando que se chegou à estrutura do fenômeno estudado (Martins \& Bicudo, 1989).

\section{Participantes}

Participaram deste estudo seis crianças que estavam finalizando o tratamento contra o câncer, com idades entre oito e treze anos, estimuladas à expressarem-se verbalmente sobre suas experiências. Estipulamos como critério de inclusão que as crianças estivessem iniciando o acompanhamento médico neste ambulatório, vindas do Ambulatório de Oncologia Pediátrica, ou seja, passando da condição de doente para a condição de curados. Estabelecemos essa fase, que é um momento de transição entre o término do tratamento e a constatação da sobrevivência.

A opção por essa faixa etária, a escolar, justifica-se por ser uma fase do desenvolvimento infantil em que a criança se expressa melhor verbalmente, possui um vocabulário mais diversificado, havendo também maior diversidade de experiência de vida.

Foram entrevistados dois meninos e quatro meninas, a maioria morava com a família nuclear (pai, mãe e irmãos), alguns apresentavam no entorno da família os avós, que provavelmente participavam do universo da criança e de seus afetos, e apenas uma criança morava com a tia e uma prima, pois, segundo ela mesma, não estava se relacionando bem com a mãe. Todas as crianças estavam frequentando a escola, embora a maioria relatasse a necessidade de interromper os estudos em algum momento do tratamento, devido às internações e/ou consultas médicas frequentes.

\section{Resultados}

Serão apresentadas a seguir as análises dos relatos obtidos a partir das entrevistas realizadas com as crianças que estavam finalizando o tratamento contra o câncer. As categorias de análise que emergiram dos relatos são apresentadas em negrito e as falas das crianças em itálico, para facilitar a compreensão. 


\section{O estar doente}

Esta categoria traz a compreensão da criança sobre como é "o estar doente" e o início de uma elaboração acerca de como isso aconteceu. Do ponto de vista existencial, "o adoecer é uma possibilidade, e sendo um fato real que pode surgir a qualquer momento da vida do ser humano, podemos concebê-lo como algo que faz parte da natureza humana" (Valle \& Françoso, 1997, p.66).

Alice, em seu relato, relaciona o surgimento da doença à briga fraterna, tendo esta um caráter punitivo, mas ao mesmo tempo a faz sentir-se igual aos outros quando refere que todos têm um tumor.

"... tudo isso começou com uma briga... acho que todo mundo tem um tumor, só que às vezes não cresce, não faz nada... mas aí meu irmão me deu um soco e o meu desenvolveu muito rápido..." (Alice, 13 anos).

A doença e o tratamento marcam tanto a vida da criança que parece inevitável falar sobre esse período. O mundo circundante da criança, seu ambiente e as relações que a criança estabelece com este apresentam-se modificados pelas restrições provocadas pela doença (Forghieri, 1993). A realização do desejo da criança aparece, de acordo com suas falas, impossibilitada pela doença, que afasta a criança de sua rotina, de seu mundo.

"Antes eu queria fazer muita coisa só que não podia... daí eu tinha que parar. Não podia ir num clube, brincar de correr, nem andar de bicicleta... se eu machucasse tinha que ficar deitada dentro de casa, parada..." (Marina, 10 anos).

"Eu não podia tomar injeção de febre amarela por causa dos remédios que tomava aqui... não podia jogar bola... não ia muito à escola porque eu estava vomitando..." (Luiz Fernando, 11 anos).

São evidenciadas as restrições no mundo de relações e o sentimento de exclusão vivenciado pelas crianças.

"Eu tinha que usar máscara, não podia ter contato com outras pessoas porque senão podia pegar doença..." (Alice, 13 anos).
Alice sente as restrições, a partir da doença, em seu mundo próprio, que se refere à relação que o indivíduo estabelece consigo, no seu ser-si-mesmo, na consciência de si e do outro (Forghieri, 1993). Refere o seu pesar com o afastamento das pessoas que, antes da doença, faziam parte de seu convívio.

"Quando eu estava doente, as pessoas me olhavam de um jeito estranho... muitas pessoas se afastaram de mim..." (Alice, 13 anos).

As inúmeras consequências sociais e psicológicas do câncer infantil em alguns momentos podem ser mais debilitantes do que a própria doença física (Patistea, 2005).

\section{Falando sobre o tratamento}

A criança com câncer se vê, de um momento para outro, em um hospital, um ambiente desconhecido, cercada por pessoas estranhas, sendo submetida a uma série de exames invasivos e dolorosos. Independentemente de sua idade e de sua capacidade de compreensão cognitiva da realidade que a rodeia, ela de algum modo se dá conta de que algo grave e temível está acontecendo com ela. Invadida pela sensação de perigo iminente, a criança tem a linha de continuidade de seu desenvolvimento subitamente rompida (Menezes, Passareli, Drude, Santos, \& Valle, 2007).

Durante as entrevistas, as lembranças da época do tratamento mostraram-se ainda muito presentes, mesmo com as crianças estimuladas a falarem sobre o futuro.

“... ah, doía muito... tem a quimioterapia e depois tem o soro e fica muito tempo... tem que ficar bastante tempo de repouso... ah, eu odeio ficar de cama... é super ruim..." (Alice, 13 anos).

"Eu fiz quimioterapia... tomei injeção nas costas..." (Jaqueline, 8 anos).

"Eu tive que fazer uma cirurgia no pescoço... eu ficava nervoso... tive que fazer quimioterapia..." (Luiz Fernando, 11 anos). 
"Eu tinha muita dor... mal-estar..." (Marina, 10 anos).

"Eu tomava remédio aqui, chegava em casa e vomitava... sentia dor..." (Luiz Fernando, 11 anos).

As crianças mostram em seus relatos, ao falarem sobre os procedimentos terapêuticos vividos, que ao final do tratamento contra o câncer já começam a espacializar o mundo hospitalar com familiaridade, revelando terem se apropriado desse universo como um recurso de enfrentamento.

\section{Simbolizando a vitória}

Esta categoria traz o mundo próprio da criança, que se caracteriza pela significação que as experiências têm para a pessoa, e pelo conhecimento de si e do mundo, ou seja, como as crianças vivenciaram o processo da doença/tratamento (Forghieri, 1993). A categoria traz o simbolismo utilizado pelas crianças como legitimação da vitória que alcançaram ao se curar. Duas crianças parecem buscar num objeto concreto, representativo da doença, um "certificado" de que passaram pelo adoecimento e alcançaram a cura.

"Eu tenho guardada lá em casa a agulha que eles usavam para dar injeção em mim..." (Marina, 10 anos).

"... eles me disseram que iam me dar a máscara, mas não me deram até hoje..." (Luiz Fernando, 11 anos).

O turbilhão de sentimentos vivenciados durante o processo iniciado com a descoberta da doença - e que se prolonga durante o extenso percurso do tratamento -, não desaparece de uma hora para outra (Menezes et al., 2007). As crianças explicitam seus sentimentos com relação ao que foi vivido e simbolizam sua vitória por meio de experiências vividas durante esse processo.

\section{Mudanças no contexto sociofamiliar}

O modo dos pais lidarem com o processo do adoecimento dos filhos é, em parte, determinado

294 pelas suas histórias e experiências passadas, seus valores e crenças pessoais (Gimenez, 1994). Esta categoria traz a percepção da criança sobre as mudanças ocorridas em sua vida, no decorrer da doença e do tratamento.

"... meu pai não está mais bebendo... minha mãe parou de brigar comigo..." (Raquel, 10 anos).

"... melhorou na minha casa, com meus amigos... na escola..." (Marina, 10 anos).

"Na minha casa as coisas mudaram bastante... eu não moro mais com minha mãe..." (Alice, 13 anos).

O câncer infantil e seu tratamento têm um impacto sistêmico sobre a organização da família, tornando tanto a criança como seus cuidadores vulneráveis ao sofrimento psíquico. Esse sofrimento vivenciado pelos familiares, cuidadores e pessoas próximas muitas vezes acarreta mudanças que são percebidas pelas crianças (Lopes \& Valle, 2001).

\section{A fé relacionada à cura}

Esta categoria embasa o modo espontâneo com que as crianças trazem um ser superior - Deus -, como fonte de apoio para a superação de sua realidade com a doença. Pedem e acreditam na possibilidade de Deus curar-Ihes e mostram sentir-se acompanhadas por ele.

$$
\begin{aligned}
& \text { “... eu pedi pra Deus e ele me ajudou. ... eu } \\
& \text { peço pra Deus me curar pra mim passar de } \\
& \text { ano..." (Raquel, } 10 \text { anos). } \\
& \text { “... eu já estou bem graças a Deus e peço } \\
& \text { pra Deus para não acontecer mais isso } \\
& \text { comigo... Deus está comigo..."(Luiz Fernando, } \\
& 11 \text { anos). } \\
& \text { “... agora, graças a Deus, não tomo mais } \\
& \text { injeção..." (Marina, } 10 \text { anos). } \\
& \text { “... eu aguentei firme graças a Deus..." } \\
& \text { (Daniel, } 10 \text { anos). }
\end{aligned}
$$

Muitas crianças que passaram pelo tratamento contra o câncer imaginam que alcançaram uma graça divina. Demonstram a percepção de que 
levam, dessa travessia dos tempos turbulentos, uma bagagem muito extensa, adquirida nos dias difíceis que renovaram sua fé no valor da vida (Menezes et al., 2007).

\section{Olhando o futuro}

Esta categoria esta relacionada à ideia de cura, de estar livre da doença, de tornar-se saudável; a criança projeta-se no futuro, redescobrindo suas possibilidades e falando de seus projetos de vida.

"... eu penso em ser feliz e ter saúde pra mim, pra minha família e... viver. Vou ajudar meu pai, minha mãe e meus irmãos e quero passar de ano..." (Raquel, 10 anos).

"Ah, tudo vai mudar, né... pra melhor... eu só sei que vai ser muito bom..." (Marina, 10 anos).

"Ah, vai ser bem melhor (futuro)... é muito bom terminar (tratamento)..." (Alice, 13 anos).

"Vai ser tudo diferente... vou poder brincar, vou jogar todo dia videogame, vou estudar muito, vou firme na escola, vou ajudar minha mãe, minha irmã e toda minha família que precisar de ajuda... Quero ser jogador de futebol." (Daniel, 10 anos).

"Vai ser bem melhor (futuro)... tudo vai melhorar..." (Jaqueline, 8 anos).

“... agora posso jogar videogame, posso brincar, jogar bola, posso fazer minha vida mudar, estudar... já estou estudando..." (Luiz Fernando, 11 anos).

Muitas dessas crianças que sobreviveram ao câncer despenderam a maior parte de suas vidas tratando da doença e precisarão reaprender a existir em sua nova condição de "curadas" (Valle, 2003). Pode ser visto nas falas das crianças que, apesar de elas terem o desafio de reaprender a viver em sua nova condição de curadas, elas veem sua vida cheia de possibilidades e mostram-se com disposição e positividade em recomeçar, acreditando que será uma etapa da vida muito melhor.

\section{Discussão}

Quando a criança está finalizando seu tratamento, em processo de cura, e se encontra sem os sintomas da doença, ainda assim permanecem, por algum período, as lembranças e as antigas referências da época do tratamento, os procedimentos invasivos, o mundo hospitalar e as impossibilidades vivenciadas. Essas lembranças se mostraram muito presentes mesmo quando as crianças foram estimuladas a falarem sobre o futuro. Ao rememorarem o tratamento, as crianças transcendem sua condição presente, voltando-se ao passado: é um constante movimento de ir e vir, para compreender a situação presente, percebido na maioria das categorias apresentadas. Adaptando-se à situação da doença, as crianças começam a espacializar o mundo hospitalar com familiaridade, mostrando terem se apropriado desse universo como possível recurso de enfrentamento.

Ao retratarem o tratamento, ficou evidente a ambivalência dos sentimentos: um período difícil, sofrido, amedrontador, com a ocorrência de alterações importantes na vida escolar e social - afastamento de alguns amigos, impossibilidade de realizar algumas atividades, reprovação do ano letivo -, mas no qual também foram construídas experiências positivas relacionadas ao enfrentamento e ao sucesso diante da doença, o que torna fundamental esse período à vida como um todo.

Ao longo de todo esse processo, em um constante aproximar-se e afastar-se das situações que envolviam o adoecer e o tratamento, as crianças se defrontaram com o paradoxo vida e morte. A possibilidade de morte, quase não falada explicitamente nos relatos, apresenta-se implícita durante o decorrer da doença e do tratamento, colocando a criança em uma condição fragilizada, vulnerável e impotente.

Em seus discursos, as crianças expressaram o desejo de retomar e assumir suas atividades que faziam e/ou pretendiam fazer antes de adoecer e que foram interrompidas ou dificultadas pela doença. As crianças debruçaram-se sobre o passado, refletiram sobre o que já viveram e projetaram suas 
expectativas sobre o que poderá acontecer. Sentem-se livres de um tratamento sofrido, visto como uma prisão.

Ao final do tratamento, quando entrevistadas, as crianças mostraram sentir-se curadas, por estarem livres dos sintomas da doença. Falaram da doença como algo que ficara em seu passado, um passado muito próximo, ainda muito presente pela rememoração do tratamento, mas ao mesmo tempo um passado que ficou para trás. Elas retrataram o sentimento de normalidade e igualdade com relação às outras crianças. A cura significa para a criança a superação de uma etapa: a doença. É como se a criança, livre dos sintomas da doença, voltasse a habitar seu mundo próprio. Sentindo-se livre da doença, a criança projeta-se no futuro e vislumbra um acontecer de possibilidades.

Ao estar com essas crianças enquanto ser-criança-com-câncer em final de tratamento e compartilhar o seu mundo através da pesquisa realizada, notou-se um amadurecimento precoce devido à experiência do adoecer na infância. Conclui-se que, apesar de terem vivenciado uma doença e tratamento tão invasivos, essas crianças mostraram sua capacidade de superação, manifestando força e coragem sem limites, mas também revelando incertezas e inseguranças com relação à continuidade de sua vida e de suas possibilidades futuras.

Adoecer com câncer é um processo gerador de dor e sofrimento para a criança e para seus familiares, mas desvela facetas da realidade que possibilitam novos olhares acerca dos recursos de enfrentamento das crianças e amplia os horizontes de intervenções na área da saúde. A partir de estudos em que a criança é convidada a falar de si, é possível ampliar a compreensão de como ela percebe o adoecimento, de quais recursos dispõe para enfrentar as situações, de como se dão as relações com as pessoas que estão com ela no dia a dia. Havendo essa compreensão ampliada da criança, faz-se possível a implementação de ações e intervenções em saúde que sejam contextualizadas e coerentes com suas necessidades e vivências, ampliando a capacidade de acolhimento e de escuta durante e também após o tratamento.

\section{Referências}

Ayoub, A. C., Fontes, A. L. C., Santos, C. A., \& Moreira, E. F. (2000). Oncopediatria e assistência de enfermagem. In A. C. Ayoub, A. L. C. Fontes, M. A. A. Silva, N. R. C. Alves, P. Gigliotte \& Y. B. Silva (Orgs.), Planejando o cuidar na enfermagem oncológica (pp.127-142). São Paulo: Lemar.

Camargo, B., \& Lopes, L. F. (2000). Pediatria oncológica: noções fundamentais para a pediatria. São Paulo: Lemar.

Carvalho, C. S. U. (2008). A necessária atenção à família do paciente oncológico. Revista Brasileira de Cancerologia, 54(1), 97-102. Recuperado em agosto 15, 2008, de http://www.inca.gov.br/rbc/n_54/v01/pdf/ revisao_7_pag_97a102.pdf

Eiser, C. (1994). Making sense of chronic disease: The eleventh Jack Tizard memorial lecture. Journal of Child Psychology and Psychiatry and Allied Disciplines, 35(8), 1373-1389.

Forghieri, Y. C. (1993). Psicologia fenomenológica: fundamentos, métodos e pesquisa. São Paulo: Pioneira.

Gimenez, M. G. (1994). Definição, foco de estudo e intervenção. In M. M. M. J. Carvalho (Org.), Introdução à Psiconcologia (pp.22-24). São Paulo: Psy.

Kennedy, R. D. (2003). Prevenção e rastreamento do câncer. In R. A. J. Spence \& P. G. Johnston (Orgs.), Oncologia (pp.47-57). Rio de Janeiro: Guanabara Koogan.

Lopes, D. P. L. O., \& Valle, E. R. M. (2001). A organização familiar e o acontecer do tratamento da criança com câncer. In E. R. M. Valle (Org.), A Psico-oncologia pediátrica (pp.13-74). São Paulo: Casa do Psicólogo.

Martins, J., \& Bicudo, M. A. V. (1989). A pesquisa qualitativa em psicologia: fundamentos e recursos básicos. São Paulo: Moraes.

Menezes, C. N. B., Passareli, P. M., Drude, F. S., Santos, M. A. S., \& Valle, E. R. M. (2007). Câncer infantil: organização familiar e doença. Revista Mal-Estar e Subjetividade, 7(3), 191-210.

Motta, A.B., \& Enumo, R. S. F. (2004). Câncer infantil: uma proposta de avaliação das estratégias de enfrentamento da hospitalização. Estudos de Psicologia (Campinas), 21(3), 193-202. doi: 10.1590/S0103-16 6X2004000300004

Nascimento, L. C. (2003). Crianças com câncer: a vida das famílias em constante reconstrução (Tese de doutorado não-publicada). Universidade de São Paulo.

National Cancer Policy Board. Institute of Medicine. (2003). Childhood cancer survivorship: Improving care and quality of life. Washington, D.C.: The National Academies Press. Retrieved September 9, 2008, from http://www.nap.edu/openbook.php?record_id=10 767\&page $=$ R1 
Ortiz, M. C. A., \& Lima, R. A. G. (2007). Experiências de familiares de crianças e adolescentes, após o término do tratamento contra câncer: subsídios para o cuidado de enfermagem. Revista Latino-Americana de Enfermagem, 15(3), 411-417.

Patistea, E. (2005). Description and adequacy of parental coping behaviors in childhood leukaemia. International Journal of Nursing Studies, 42, 283-296.

Spinetta, J. J., Masera, G., Eden, T., Oppenheim, D., Martins, A. G., Dongen-Melman, J. V., et al. (2004). Recusa, não-cooperação e abandono de tratamento em crianças e adolescentes com câncer. In Sociedade Internacional de Oncologia Pediátrica (SIOP). Orientações sobre aspectos psicossociais em oncologia pediátrica (pp.57-63). [s.I.]: SIOP.

Teixeira, R. A. P., Bruniera, P., Cusato, M. P., \& Borsato, M. L. (2000). Câncer infantil. In F. F. Baracat, H. J.
Fernandes Júnior \& M. J. Silva (Orgs.), Cancerologia atual: um enfoque multidisciplinar (pp.426-451). São Paulo: Roca.

Valle, E. R. M. (1997). Câncer infantil: compreender e agir. Campinas: Editorial Psy.

Valle, E. R. M. (2003). Vivências da família da criança com câncer. In M. M. M. J. Carvalho (Org.), Introdução à psiconcologia (pp.219-242). Campinas: Livro Pleno.

Valle, E. R. M., \& Françoso, L. P. C. (1997). Psicologia e enfermagem: a questão do adoecer. Revista Psicologia Argumento, 15(20),61-70.

Recebido em: 20/3/2012

Versão final em: 8/5/2012

Aprovado em: 28/5/2012 
